\title{
ESTIMASI KONSEPTUAL BIAYA PEMBANGUNAN DRAINASE DI WILAYAH KOTA SUKABUMI MENGGUNAKAN MODEL
}

\author{
Paikun dan Cevi Andrian \\ Program Studi Teknik Sipil, Universitas Nusa Putra \\ Email: paikun@nusaputra.ac.id
}

\begin{abstract}
ABSTRAK: Penataan sistem penyediaan air dibidang tata ruang, pertanian dan lainnya pada umumnya menggunakan drainase, oleh karena itu pembangunan drainase merupakan bagian penting. Pembangunan saluran drainase memerlukan biaya, tetapi mengestimasi biaya membutuhkan data perencanaan secara detail, perlu analisa biaya material, tenaga kerja, alat, dan membutuhkan waktu yang cukup lama. Pada tahap awal penetapan anggaran biaya sering belum tersedia data gambar, sehingga tidak ada dasar untuk menentukan jumlah anggaran. Oleh karena itu penelitian ini penting untuk menghasilkan model, sebagai rumus untuk memprediksi biaya tahap awal ketika data gambar belum ada. Analisis regresi adalah metode yang dipergunakan untuk menghasilkan model dalam penelitian ini. Data analisis regresi menggunakan data rencana anggaran biaya terperinci pembangunan drainase berdasarkan populasi pembangunan drainase tahun 2018-2020 diwilayah kota Sukabumi. Memprediksi biaya pembangunan drainase menggunakan model hasil penelitian ini, cukup memasukkan volume pembangunan drainase, maka total biaya pembangunan dapat di ketahui dengan cepat. Model ini khusus untuk memprediksi biaya pembangunan drainase terbuka dengan spesifikasi pasangan batu yang di plester aci, sedangkan untuk memprediksi biaya pembangunan derainase tertutup seperti drainase gorong-gorong, u-dits, gravel dan lain-lain perlu penelitian lebih lanjut, karena spesifikasinya berbeda.
\end{abstract}

Kata kunci: estimasi biaya; pembangunan drainase; analisis regresi; regresi linier

\section{CONCEPTUAL ESTIMATE OF DRAINAGE DEVELOPMENT COSTS IN THE SUKABUMI CITY REGION USING THE MODEL}

\begin{abstract}
Water supply systems in spatial planning, agriculture, and other areas generally use drainage, therefore drainage development is a very important part. The construction of drainage channels requires costs, but estimating costs requires detailed planning data, requires analysis of material costs, labor, tools, and requires a long time. At the initial stage of determining the cost budget, drawing data is often not available, so there is no basis for determining the budget amount. Therefore, this research is important to produce a model, as a formula for predicting costs in the early stages when the image data does not yet exist. Regression analysis is a method used to produce models in this study. Regression analysis data uses detailed budget plan data for drainage development based on the population of drainage development in 2018-2020 in the city of Sukabumi. Predicting the cost of drainage construction using the model from this research, it is enough to enter the volume of drainage development, then the total cost of drainage development can be found quickly. This model is specifically for predicting the cost of building open drainage with the specifications of masonry covered with a plaster, while predicting the cost of building closed drainage such as culvert drainage, u-dits, gravel, and others, requires further research because the specifications are different.
\end{abstract}

Keywords: estimated costs; drainage construction; regression analysis; linear regression 


\section{PENDAHULUAN}

Saluran drainase merupakan sebuah kebutuhan bagi setiap wilayah. Dampak negatif seperti kelebihan air permukaan, banjir, merusak jalan lingkungan dan lainlain yang dapat menggangu aktifitas warga dapat dikendalikan menggunakan drainase (Wahyudi dan Adi, 2015;2). Sehingga pembangunan saluran drainase dapat dinyatakan sebagai aktifitas yang memberikan manfaat secara umum bagi kegiatan kehidupan manusia (Novrianti, 2017).

Pembangunan saluran drainase membutuhkan biaya, sehingga memprediksi biaya pembangunan saluran drainase sangat penting. Untuk dapat memprediksi biaya perlu data pendukung seperti data gambar detail, identifikasi kuantitas pekerjaan, dan harus melakukan analisa harga satuan setiap item pekerjaan baru kemudian dapat terprediksi rencana anggaran biaya (RAB) pekerjaan saluran drainase (Falah dan Musyafa, 2019).

Dalam penganggaran biaya proyek tahap awal para pemangku kebijakan pada umumnya perlu menentukan biaya proyek, sedangkan kondisinya belum tersedia perencanaan proyek secara detail, sehingga Analisa biaya proyek belum bisa dilakukan. Dalam kondisi ini penentuan anggaran proyek sering tidak akurat, oleh karena itu perlu ada rumus untuk menentukan anggaran biaya proyek pada tahap konseptual.

Penelitian sebelumnya telah menghasilkan model untuk memprediksi biaya proyek pada tahap konseptual sebelum ada data perencanaan secara detail pada proyek pembangunan rumah (Paikun dkk, 2017), model estimasi biaya pembangunan ruko (Paikun dkk 2018;Paikun dkk, 2019), model estimasi biaya proyek pemeliharaan jalan (Rosmunadi dan Wateno, 2020), model estimasi biaya konstruksi Gedung pemerintah (Astana, 2017), model estimasi biaya pembangunan dermaga (Roring, 2019), dan banyak penelitian lain tentang model estimasi biaya pembangunan dengan jenis proyek yang berbeda-beda.

Secara umum model yang dihasilkan oleh peneliti terdahulu menyatakan bahwa model dapat digunakan dengan akurat, karena hanya terdapat beberapa persen saja selisihnya dengan faktual. Diantaranya bahwa estimasi biaya proyek jembatan beton bertulang menggunakan model hanya terdapat selisih antara $-3,37 \%$ sampai $+1,69 \%$ (Khamistan 2019). Pekerjaan lapis perkerasan lentur menggunakan model dinyatakan akurat (Wulandari dkk 2020), serta banyak penelitian lain yang menyatakan bahwa estimasi menggunakan model secara umum dapat dinyatakan akurat (Pontan dan Yulianisa, 2019; Saputro dan Huda, 201; Falahis dkk, 2015).

Berdasarkan permasalahan yang disampaikan dalam penelitian ini, serta berdasarkan referensi penelitian sebelumnya dengan hasil penelitian mendapatkan model yang dapat digunakan untuk estimasi biaya proyek dengan akurat, sehingga penelitian ini penting untuk menghasilkan model sebagai rumus estimasi biaya proyek pada pembangunan saluran drainase di kota Sukabumi.

Hasil penelitian ini diharpkan dapat berkontribusi dan dapat dimanfaatkan oleh siapapun termasuk oleh pihak pemangku kebijakan dalam menganggarkan biaya proyek pembangunan saluran drainasi pada tahap awal atau tahap penganggaran.

Hipotesis penelitian ini adalah, apabila diketahui volume pekerjaan saluran drainase, maka dapat diprediksi jumlah biaya menggunakan model.

Penelitian ini bertujuan untuk menghasilkan model estimasi biaya pekerjaan saluran drainasi khusus untuk drainase terbuka menggunakan spesifikasi pasangan batu dengan finishing plester aci.

\section{METODE}

Penelitian ini diawali dengan pengumpulan data rencana anggran biaya (RAB) secara keseluruhan dari tahun 2018 sampai dengan 2020 yang dilaksanakan oleh Bina Marga, dengan melakukan obsevasi dan wawancana terhadap pelaksana pembangunan. Data selanjutnya secara spesifik dikelompokkan sesuai fungsinya masing-masing.

Pengumpulan data terdiri dari tahun yang berbeda-beda, yaitu tahun 2018 sampai dengan tahun 2020, sehingga perlu menarik ke tahun yang sama yaitu tahun 2020 menggunakan metode Future Value (FV), dengan memperhitungkan laju inflasi 
sebagai dasar penentuan biaya dari tahun sebelumnya ke tahun yang akan di prediksi.

Data selanjutnya diproses menjadi variabel-variabel, yang terdiri dari variabel bebas dan variabel tergantung. Variabel keputusan ditentukan bahwa biaya pembangunan saluran drainasi sebagai variabel terikat dan dinyatakan dengan Y, sedangkan variabel bebas adalah volume drainase yang dinyatakan dengan $X$.

Data selanjutnya dianalisis statistik menggunakan metode regresi linear untuk mendapatkan model.

\section{Pengumpulan Data}

Untuk menghasilkan model maka membutuhkan data, dan data terdiri dari:

1. Data dari beberapa proyek yang sejenis dengan tahun yang berbeda atau sama dengan jumlah data 14 yang dilaksanakan oleh Bina Marga.

2. Data berupa Rencana Anggaran Biaya (RAB) lengkap dengan informasi proyek, dengan biaya, tidak termasuk Pajak Pertambahan Nilai (PPN).

3. Data inflasi tahunan sesuai dengan tahun pelaksanaan data proyek yang ditinjau.

\section{Proses Data dan Analisis}

Proses data dan analisis dilakukan melalui tahapan sebagai berikut:

1. Identifikasi variabel yang terdiri dari variabel tergantung dan variabel bebas, atau variabel $Y$ dan variabel $X$.

2. Perhitungan Pengaruh Time Value Perhitungan dilakukan untuk menyamakan nilai uang karena data berasal dari tahun yang berbeda-beda. Perhitungan dilakukan dengan rumus:

$\mathrm{FV}=\mathrm{P} 0(1+\mathrm{i})^{\mathrm{n}}$

Keterangan:

$\begin{array}{ll}\text { FV } & \text { : Future Value } \\ \text { P0 } & \text { : Nilai saat ini } \\ \text { I } & \text { : Tingkat suku bunga } \\ \text { n } & \text { : Tahun proyeksi }\end{array}$

3. Untuk mencari hubungan antara satu variabel bebas $(\mathrm{X})$ dengan variabel tergantung (Y), hubungan positif atau negative, dan memprediksi nilai dari variabel tergantung, menggunakan analisis regresi linear sederhana. Simulasi model regresi seperti persamaan 2 .

$$
\begin{aligned}
& \mathrm{Y}=\mathrm{a}+\mathrm{b} . \mathrm{X} \\
& \text { Keterangan: } \\
& \mathrm{Y} \quad=\text { Variabel tergantung (terikat) } \\
& \mathrm{X}=\text { Variabel pengaruh } \\
& \mathrm{a} \quad=\text { nilai tetap variabel tergantung } \\
& \mathrm{b}=\text { Nilai tetap variabel pengaruh }
\end{aligned}
$$

4. Interprestasi output program Statistik

a. Bagian Model summary, yang di tinjau nilai Korelasi (R), sebagai penentu kekuatan hubungan antara variabel tergantung dengan variabel pengaruh. Jika nilai $\mathrm{R}$ mendekati 1 , maka memiliki hubungan yang sangat kuat antara variabel tergantung dengan variabel pengaruh.

b. Bagian analisi Anova di tinjau nilai Signifikansi (sig), Nilai sig harus lebih kecil dari nilai a (Alfa) yaitu nilainya 0,05 atau $5 \%$ (sig. < 0,005)

c. Analisis bagian Coeffecients mendapatakan nilai koefisien Data sebagai model ini: $\mathrm{Y}=\mathrm{a}+\mathrm{bx}$

5. Pengujian

a. Uji T-tabel yaitu mambandingkan antara $\mathrm{T}$ hitung dengan $\mathrm{T}$ tabel, untuk mengetahui pengaruh dari variable pengaruh secara individu.

b. Uji akurasi biaya estimasi, yaitu untuk menguji seberapa akurat hasil perhitungan estimasi biaya dengan meggunakan model. Pengujian dilakukan dengan mambandingkan hasil estimasi menggunakan model dengan perhitungan mengunakan cara konvensional.

Melalui tahapan-tahapan ini maka akan mendapatkan model estimasi biaya pembangunan saluran drainase terbuka menggunakan spesifikasi pasangan batu dengan finshing plester aci. Proses penelitian ini secara singkat di jelaskan pada Gambar 1. 


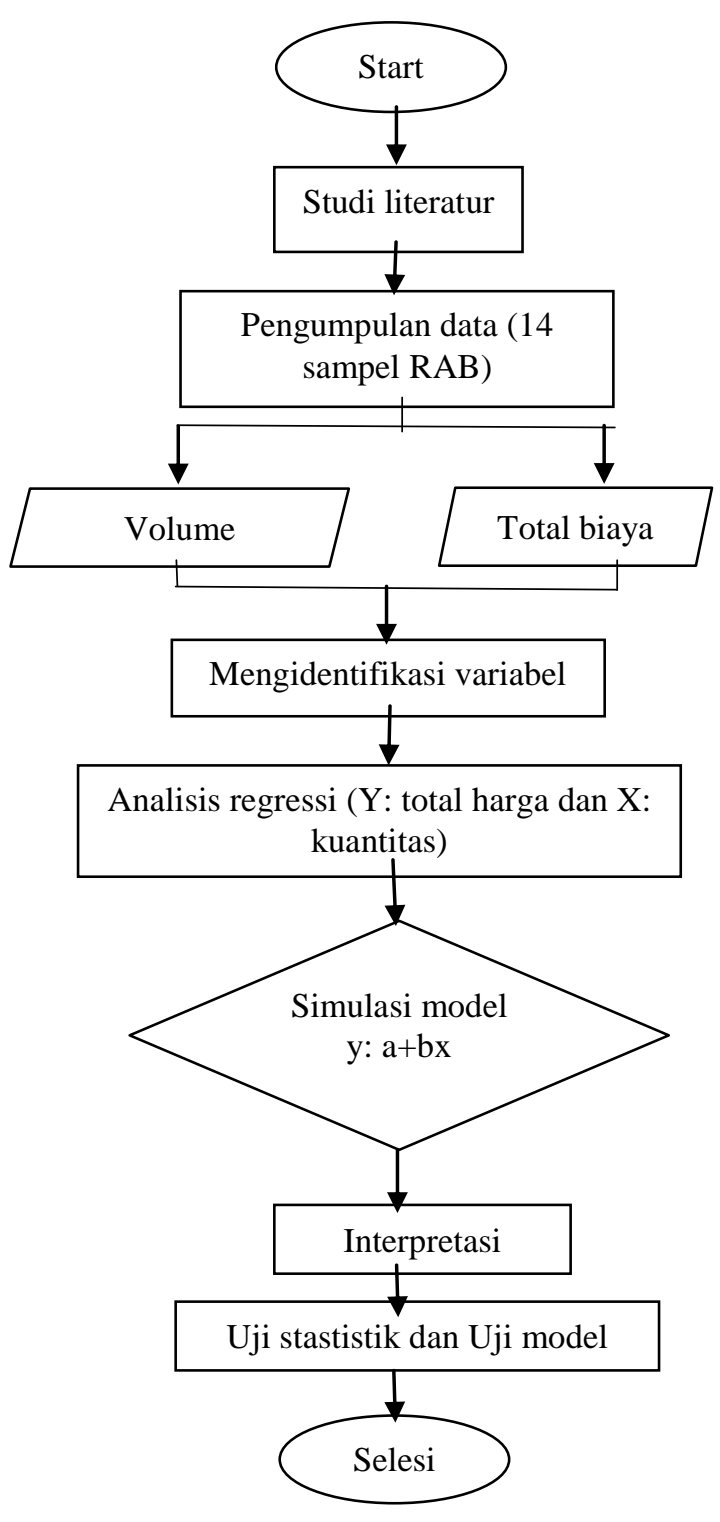

Gambar 1: Proses menghasilkan model

\section{HASIL DAN PEMBAHASAN \\ Data Penelitian}

Data penelitian adalah data rencana anggaran biaya pembangunan drainasi di wilayah kota Sukabumi, yang telah diproses dengan cara pengelompokan data menjadi data total biaya dan kuantitas pekerjaan drainase, kemudian di rekap seperti Table 1.
Tabel 1. Rekap pengumpulan data

\begin{tabular}{lccr}
\hline \multirow{2}{*}{ No } & \multirow{2}{*}{ Tahun } & Kuantitas/m3 & \multicolumn{1}{c}{ Toatal biaya } \\
\cline { 3 - 4 } & & $(\mathbf{X})$ & $(\mathbf{Y})$ \\
\hline 1 & 2018 & 100,81 & $101.867 .866,60$ \\
2 & 2018 & 101,81 & $38.529 .891,00$ \\
3 & 2018 & 102,81 & $38.351 .132,50$ \\
4 & 2018 & 103,81 & $62.237 .987,50$ \\
5 & 2018 & 104,81 & $145.673 .901,25$ \\
6 & 2018 & 105,81 & $73.515 .555,20$ \\
7 & 2018 & 106,81 & $53.753 .322,80$ \\
8 & 2018 & 107,81 & $78.428 .380,00$ \\
9 & 2019 & 108,81 & $97.945 .873,85$ \\
10 & 2019 & 109,81 & $101.088 .778,51$ \\
11 & 2019 & 110,81 & $61.452 .038,52$ \\
12 & 2019 & 111,81 & $75.696 .594,98$ \\
13 & 2019 & 112,81 & $82.631 .418,92$ \\
14 & 2019 & 113,81 & $64.433 .965,77$ \\
\hline
\end{tabular}

\section{Proyeksi Menggunakan Future Value}

Perhitungan Pengaruh Time Value, Perhitungan dilakukan untuk menyamakan nilai uang karena data berasal dari tahun yang berbeda-beda. Perhitungan dilakukan dengan rumus persamaan 1. Untuk melakukan proyeksi harga dari tahun 2018 s.d. 2019 keharga pada tahun 2020, dibutuhkan data inflasi tahunan. Data inflasi berdasarkan Badan Pusat Statistik (BPS), ditunjukan pada Tabel 2, dan hasil peroyeksi anggaran lihat table 3 .

Tabel 2. Data faktor inflasi umum

\begin{tabular}{c|l|c}
\hline \multicolumn{3}{c}{ Data Suku Bunga Investasi (Sumber BPS) } \\
\hline \multicolumn{1}{c|}{ Keterangan } & Tahun & I/tahun \\
\hline Bank Umum - Investasi & 2018 & 10,41 \\
Bank Umum - Investasi & 2019 & 10,195 \\
\hline
\end{tabular}

Tabel 3. Data proyeksi tahun 2020

\begin{tabular}{lccr}
\hline \multirow{2}{*}{ No } & \multirow{2}{*}{ Tahun } & $\begin{array}{c}\text { Kuantitas } \\
\mathbf{l} \mathbf{3} 3\end{array}$ & \multicolumn{1}{c}{ Toatal biaya } \\
\cline { 3 - 4 } & & $(\mathbf{X})$ & \multicolumn{1}{c}{$(\mathbf{Y})$} \\
\hline 1 & 2020 & 100,81 & $124.180 .679,14$ \\
2 & 2020 & 31,05 & $46.969 .355,41$ \\
3 & 2020 & 27,38 & $46.751 .442,22$ \\
4 & 2020 & 54,95 & $75.870 .397,74$ \\
5 & 2020 & 147,34 & $177.581 .847,88$ \\
6 & 2020 & 70,56 & $89.618 .167,90$ \\
7 & 2020 & 46,85 & $65.527 .279,15$ \\
8 & 2020 & 79,16 & $95.607 .082,17$ \\
9 & 2020 & 93,28 & $107.931 .455,69$ \\
10 & 2020 & 91,12 & $111.394 .779,47$ \\
11 & 2020 & 58,15 & $67.717 .073,84$ \\
12 & 2020 & 64,52 & $83.413 .862,83$ \\
13 & 2020 & 66,42 & $91.055 .692,08$ \\
14 & 2020 & 56,46 & $71.003 .008,58$ \\
\hline
\end{tabular}




\section{Identifikasi Variabel}

Variabel perhitungan yang akan digunakan adalah sebagai berikut:

1. Biaya total proyek, sebagai variable terikat dengan simbol (Y)

2. komponen kuantitas $\left(\mathrm{m}^{3}\right)$, sebagai variabel bebas dengan simbol (X),

Setelah mendapatkan rekapitulasi data diatas, selanjutnya dilakukan perhitungan persamaan linier terhadap total biaya sebagai variabel (Y) dengan kuantis sebagai variabel (X). Hipotesis apakah (X) mampu mengambarkan atau menjelaskan (Y).

\section{Output Analisis Stastistik}

Interpretasikan output analisis regsesi yang di hasilkan oleh program statistik dimulai dari output variables entered seperti ditampilkan pada Tabel 4.

Tabel 4. Variables entered

\begin{tabular}{|c|c|c|c|}
\hline \multicolumn{4}{|c|}{ Variables Entered/Removed $^{\mathrm{a}}$} \\
\hline Model & $\begin{array}{c}\text { Variables } \\
\text { Entered }\end{array}$ & $\begin{array}{l}\text { Variables } \\
\text { Removed }\end{array}$ & Method \\
\hline 1 & \multicolumn{2}{|l|}{$\begin{array}{c}\text { Volume / } \\
\mathrm{m}^{\mathrm{b}}\end{array}$} & Enter \\
\hline \multicolumn{4}{|c|}{ a. Dependent Variable: total biaya } \\
\hline \multicolumn{4}{|c|}{ b. All requested variables entered. } \\
\hline
\end{tabular}

Hasil analisis seperti ditunjukan pada Tabel 4, diketahui bahwa variabel yang kita masukkan yaitu kuantitas sebagai variable pengaruh (X).

Tabel 5. model summary

\begin{tabular}{ccccc}
\hline \multicolumn{5}{c}{ Model Summary } \\
\hline Mod & $\mathrm{R}$ & $\mathrm{R}$ & Adjusted & Std. Error of \\
el & & Square & R Square & the Estimate \\
1 & .993 & 0,985 & 0,984 & 4304179,063 \\
& & & & 90 \\
\hline
\end{tabular}

a. Predictors: (Constant), Volume / m3

Berdasarkan hasil analisis seperti ditunjukan pada Tabel 5, diketahui bahwa nilai $\mathrm{R}$ sebesar 0.993 mengandung arti bahwa kuantitas pembangunan saluran drainase dapat menjelaskan total biaya sebesar $99.3 \%$. sedangkan sisanya $5 \%$ dipengaruhi oleh factor lain selain model. Dasar pengambilan keputusan korelasi menggunakan nilai $\mathrm{R}$ adalah:

1) $0,000-0,199=$ sangat rendah

2) $0,400-0,599=$ sedang

3) $0,600-0,799=$ kuat

4) $0,800-1,000 \quad=$ sangat kuat

(Gozali 2001) dan (Sugiyono 2011).
Sehingga dapat dinyatakan bahwa hubungan kuantitas pekerjaan saluran drainase terhadap total biaya pembangunan saluran drainase sangat kuat.

Analisis ANOVA berfungsi untuk menguji $F$ dan menguji signifikansi. Uji ANOVA seperti ditampilkan pada Tabel 6

\begin{tabular}{llllll}
\multicolumn{5}{c}{ Tabel 6. Analisis ANOVA } \\
\hline Model & Sum of & df & Mean & F & Sig. \\
& Squares & & Square & & \\
\hline Regression & 14847920 & 1 & 148479 & 801,466 & $.000^{\text {b }}$ \\
& 497351 & & 2049735 & & \\
& 800,000 & & 1800,000 & & \\
\hline Residual & 2223114 & 12 & 185259 & & \\
& 88969 & & 57414 & & \\
& 518,000 & & 126,500 & & \\
\hline Total & 1507023 & 13 & & & \\
& 1986321 & & & \\
\hline
\end{tabular}

Berdasarkan analisis Anova diketahui bahwa nilai $\mathrm{F}$ tes (F hitung) adalah 801,466, dan nilai signifikansi sebesar 0.000 , dengan probabilitas 0,05 , menunjukan bahwa $\mathrm{F}$ hitung > F tabel $(801,466>2,17)$, dan signifikansi $0,05>0,000$ sehingga dapat dinyatakan bahwa model yang dihasilkan dapat dipergunakan.

Untuk menentukan model estimasi biaya pembangunan saluran drainase selanjutnya perlu analisis koefisien pada statistik seperti ditunjukan pada Tabel 7.

Tabel 7. Analisis Coeffecients

\begin{tabular}{lll}
\hline \multirow{2}{*}{ Model } & \multicolumn{2}{c}{ Ustandardized Coefficients } \\
\cline { 2 - 3 } & \multicolumn{1}{c}{ B } & \multicolumn{1}{c}{ Std.eror } \\
\hline 1(Constant) & 12605239,294 & 2953476,033 \\
Volume / m3 & 1092349,315 & 38585,049 \\
\hline
\end{tabular}

Berdasarkan output analisis koefisien seperti pada Tabel 7 didapat persamaan regresi yaitu sebuah model sebagai berikut:

$\mathrm{Y}=\mathrm{a}+\mathrm{bx}$

$\mathrm{a}=12605239,294$

$\mathrm{b}=1092349,315$

Sehingga model estimasi biaya pembangunan saluran drainase adalah:

$\mathrm{Y}=12605236.294+1092349.315 . \mathrm{X}$

keterangan:

$\mathrm{Y}=$ Biaya pembangunan proyek drainase $\mathrm{X}=$ Quantity atau volume 


\section{Pengujian}

Pengujian model ini mengunakan 2 pengujian yaitu uji T-Hitung dan uji akurasi model.

1. Uji Stastistik (T-Hitung)

Uji T-Hitung untuk mengetahui apakah variabel kuantitas pekerjaan saluran drainase mampu memprediksi total biaya pembangunan drainase atau tidak. Dasar pengambilan keputusan hipotesis adalah apabila koefesien regresi tidak signifikan maka H0 diterima dan $\mathrm{H} 1$ ditolak, dan apabila koefesien regresi signifikan maka H1 diterima dan H0 ditolak. Telah ditunjukan pada Tabel 6 bahwa signifikansi $0,000<0,05$ sehingga $\mathrm{H} 1$ diterima

Dasar pengambilan keputusan uji $\mathrm{T}$ Hitung dengan probabilitas 0,05 maka $\mathrm{H} 0$ diterima apabila $\mathrm{T}$ hitung $<\mathrm{T}$ tabel, dan $\mathrm{H} 1$ diterima apabila $\mathrm{T}$ hitung $>$ Ttabel. Hasil uji $\mathrm{T}$ seperti telah ditunjukan pada Tabel 6 bahwa T-Hitung >T-Tabel (801,466 >2,17), Untuk mecari T-tabel, dapat dihitung menggunakan persamaan 3 :

$$
\text { df }=n-k
$$

Kemudian perlu mencari taraf signifikan untuk dua sisi sebesar; $0.05: 2=0.025$ (kolom 0,025)

Keterangan:

Taraf signifikan (2 sisi), Sig 5\% atau 0.05

Untuk mencari nilai $\mathrm{t}$ tabel dengan melihat tabel Seperti ditampilkan pada Gambar 2.

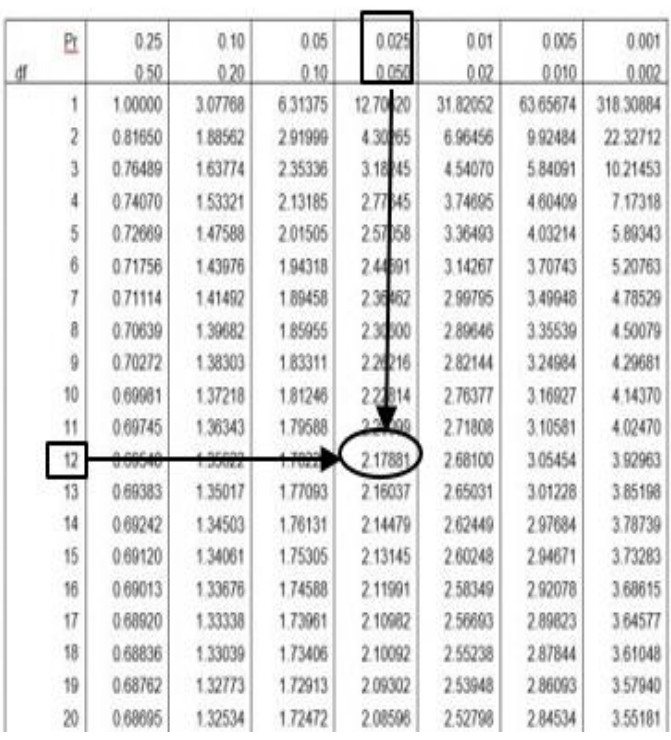

Gambar 2. Penentuan nilai T-tabel

Dari Gambar 2 menunjukan bahwa nilai T-Tabel adalah 2,17 sedangkan nilai $\mathrm{T}$ Hitung adalah 801,466, sehingga 801,466 $>2,17$ )

2. Uji akurasi model estimasi

Uji akurasi model estimasi yaitu mambandingkan anatra perhitungna estimasi menggunakan model (ev) dengan perhitungan mengunakan cara konvensional (AV), lalu di hitung nilai slisih, standar eror. Uji akurasi model seperti ditampilkan pada Tabel 8.

Tabel 8. Rekap data hasil pengujian

\begin{tabular}{|c|c|c|c|c|c|}
\hline $\begin{array}{c}\text { Kuantitas } \\
/ \mathbf{m 3}\end{array}$ & Total Aktual & Toatal Biaya & Slilih (Rp) & $\begin{array}{c}\text { Standar eror } \\
(\%)\end{array}$ & Akurasi (\%) \\
\hline & AV & EV & & & \\
\hline$(\mathrm{X})$ & Sesuai RAB & Menggunakan Model & EV-AV & $\begin{array}{l}(\mathrm{EV}-\mathrm{AV}) / \mathrm{AV} \mathrm{x} \\
100\end{array}$ & $\begin{array}{l}100 \% \text {-Std. } \\
\text { eror }\end{array}$ \\
\hline 100,81 & 124.180 .679 & 122.724 .971 & -1.455 .708 & $-1,17$ & 98,83 \\
\hline 31,05 & 46.969 .355 & 46.522 .683 & -446.673 & $-0,95$ & 99,05 \\
\hline 27,38 & 46.751 .442 & -42.513 .761 & -4.237 .682 & $-9,06$ & 90,94 \\
\hline 54,95 & 75.870 .398 & -72.629 .831 & -3.240 .567 & $-4,27$ & 95,73 \\
\hline 147,34 & 177.581 .848 & 173.551 .984 & -4.029 .864 & $-2,27$ & 97,73 \\
\hline 70,56 & 89.618 .168 & 89.681 .404 & 63.236 & 0,07 & 99,93 \\
\hline 46,85 & 65.527 .279 & 63.781 .802 & -1.745 .477 & $-2,66$ & 97,34 \\
\hline 79,16 & 95.607 .082 & 99.075 .608 & 3.468 .526 & 3,63 & 96,37 \\
\hline 93,28 & 107.931 .456 & 114.499 .580 & 6.568 .125 & 6,09 & 93,91 \\
\hline 91,12 & 111.394 .779 & 112.140 .106 & 745.326 & 0,67 & 99,33 \\
\hline 58,15 & 67.717 .074 & 76.125 .349 & 8.408 .275 & 12,42 & 87,58 \\
\hline 64,52 & 83.413 .863 & 83.083 .614 & -330.249 & $-0,40$ & 99,6 \\
\hline 66,42 & 91.055 .692 & 85.159 .078 & -5.896 .614 & $-6,48$ & 93,52 \\
\hline 56,46 & 71.003.009 & 74.279.279 & 3.276 .270 & 4,61 & 95,39 \\
\hline \multicolumn{4}{|c|}{ nilai rata- rata } & $3,91 \%$ & $96,08 \%$ \\
\hline
\end{tabular}


Pada Tabel 10, diperoleh nilai rata-rata standar eror 3,91 \% dan akurasi sebesar $96,08 \%$, sehingga dapat di simpulkan bahwa model ini cukup akurat untuk di pergunakan.

\section{SIMPULAN}

Penelitian ini telah menghasilkan solusi atas permasalahan dalam menetapakan jumlah biaya yang kompleks dan sulit apabila tidak ada data perencanaan secara lengkap. Penelitian ini telah menghasilkan model untuk memprediksi biaya pembangunan drainase pada tahap konseptual dengan memasukan data kuantitasnya pekerjaan saluran drainase terbuka. Model ini menjelaskan bahwa kuantitas pekerjaan saluran drainase berpengaruh sebesar 99,84\% terhadap total biaya proyek, sedangkan sebesar $0.06 \%$ dipengaruhi oleh sebab-sebab lain selain model. Mempunyai tingkat hubungan yang sangat kuat dengan nilai $\mathrm{F}$ tes ( $\mathrm{F}$ hitung $=$ 801,466), signifikansi sebesarar 0.000 $<0,005$, memiliki standar eror $3,91 \%$ serta memiki tingkat akurasi sebesar $96.08 \%$, sehingga model ini dapat digunakan untuk memprediksikan total biaya pembangunan drainase. Model hasil penelitian ini adalah: $\mathrm{Y}=12605236.294+1092349.315 \mathrm{X}$

Penggunaan model ini khusus untuk memprediksi biaya pembangunan drainase terbuka dengan spesikasi pasangan batu finishing pelsteran aci. Untuk memprediksi biaya pembangunan derainase tertutup seperti drainase gorong -gorong, u-dit, grevel dan lain-lain perlu penelitian lebih lanjut.

\section{UCAPAN TERIMA KASIH}

Penelitian ini didanai oleh Universitas Nusa Putra. Terima kasih disampaikan kepada Dr. Kurniawan ST., M.Si., MM Rektor Universitas Nusa Putra, dan ucapan terima kasih kepada direktur LPPM Universitas Nusa Putra yang telah mendukung sepenuhnya terhadap pelaksanaan dan tercapainya penelitian ini.

\section{DAFTAR PUSTAKA}

Astana I. N. Y 2017. Estimasi Biaya Konstruksi Gedung Dengan Cost Significant Model. Jurnal Riset Rekayasa Sipil Universitas Sebelas Maret $1 \quad$ September 2017 https://jurnal.uns.ac.id/jrrs/index

Falah dan Mussyafa', 2019. Analisis Biaya Pekerjaan Drainase Berdasarkan Metode Konvensional Dengan Metode Pracetak U Ditch (Analysis Of The Cost Of Carrying Out Drainage Work Based On Conventional Methods With Precast Methods).

https://dspace.uii.ac.id/handle/12345678 9/15993? show=full

Falahis V. D, Sugiyarto S, Laksito B, 2015, Cost Significant Model Sebagai Dasar Permodelan Estimasi Biaya Konstruksi Jembatan Beton Bertulang, e-Jurnal Matriks Teknik Sipil, Universitas Sebelas Maret, Surakarta. https://jurnal.uns.ac.id/matriks/article/vi ew/37224

Ghozali. 2001 "Analisis Multivariate Program SPSS 19": Badan Penerbit Universitas Diponegoro Semarang.

Khamistan 2019. Analisis Estimasi Biaya Dengan Metode Cost Significant Model Sebagai Dasar Perhitungan Konstruksi Jembatan Beton Bertulang Di Kabupaten Aceh Tamiang. http://teras.unimal.ac.id/index.php/teras larticle/view/168

Novrianti N. 2017. Pengaruh Drainase Terhadap Lingkungan Jalan Mendawai dan sekitar Pasar Kahayan. Media Ilmiah Teknik Lingkungan (MITL), 2(1), 31-36. https://doi.org/10.33084/mitl.v2i1.130. http://journal.umpalangkaraya.ac.id/inde x.php/mitl/article/view/130

Paikun, Kadri $\mathrm{T}$ and Sugara R. D.H, "Estimated budget construction hou sing using linear regression model easy and fast solutions accurate," 2017 International Conference on Computing, Engineering, and Design (ICCED), Kuala Lumpur, Malaysia, 2017, pp. 1-6, doi: 10.1109/CED.2017.8308095 
Paikun, Firmansyah D, Sholihah S. M, Faisal U, Jasmansyah and Kadri T, "Conceptual Estimation of Cost Significant Model on Shop-Houses Construction," 2018 International Conference on Computing, Engineering, and Design (ICCED), Bangkok, Thailand, 2018, pp. 187-192, doi: 10.1109/ICCED.2018.00044

Paikun, Rahayu S, Selpi A, Awalia A and Jasmanyah, "Quick Ways to Calculate Shophouse Construction Project Materials Using Regression Analysis Program," 2019 5th International Conference on Computing Engineering and Design (ICCED), Singapore, 2019, pp. 1-6, doi: 10.1109/ICCED46541.2019.9161083

Pontan, D. dan Yulianisa, I. 2019. Model Estimasi Biaya Renovasi Pekerjaan Rumah Tinggal Dengan Menggunakan Cost Significant Models. Prosiding Seminar Nasional Pakar 2019 Buku I. https://trijurnal.lemlit.trisakti.ac.id/pakar /article/view/4155

Roring H. 2019. Estimasi Biaya Konstruksi Dermaga Dengan Metode Cost Significant Model. Jurnal Ilmiah Realtech, 15(1), 47-52. Retrieved from https://ejournal.unikadelasalle.ac.id/rea ltech/article/view/83

Rosmunadi dan Wateno O. 2020. Analisis Estimasi Biaya Proyek Pemeliharaan Jalan Dengan Metode Cost Significant Model Pada Pelaksanaan Jalan Lintas Utara Provinsi Jawa Timur. Masters thesis, Untag Surabaya. http://repository.untag-sby.ac.id/3260/

Saputro W. D dan Huda M, 2019. "Perbandingan Anggaran Biaya Proyek Perumahan Di Surabaya Dengan Metode Cost Significant ModeL" junal rekayasa dan manajemen konstruksi, $\begin{array}{llll}\text { vol. } & 7 & \text { No. } & \text { 3, }\end{array}$ https://journal.uwks.ac.id/index.php/axi al/article/view/777

Sugiyono. 2011, "Statika Untuk Penelitian”: CV. Alfabeta, Bandung

Wahyudi dan Adi. 2016. DRAINASE SISTEM POLDER. Cetakan pertama: Juli 2016. Penerbit: EF PRESS DIGIMEDIA. ISBN. 978-602-1145-78-4. http://research.unissula.ac.id/file/publik
asi/210200030/4149Buku Prof IMAM ISI_CETAK.pdf

Wulandari N. K. H; Sudiarta, I K; Setyono, E Y, 2020. Model Estimasi Biaya Konseptual Pekerjaan Lapis Perkerasan Lentur (Studi Kasus Peningkatan Jalan Kabupaten Bangli). Proceedings, [S.l.], v. 1, n. 1, p. 145-150, jan. 2020. Available at: <http://ojs.pnb.ac.id/index.php/Proceedi ngs/article/view/1676>. Date accessed: 25 feb. 